\title{
Memória ficcional da Shoah: Peças em fuga
}

Fictional memory of Shoah: Peças em fuga

Vívien Gonzaga e Silva*

Resumo: Ler um romance rigorosamente como ficção é o nosso dever de leitores; produzir ficções capazes de desafiar o nosso senso de realidade, a nossa visão do mundo e da história, é, por assim dizer, o estrito ofício do escritor. No romance Peças em fuga, de Anne Michaels, três homens, Jakob, Athos e Ben - suas criaturas de papel -, se entregam a esse ofício. Este artigo analisa, nesse romance, a memória ficcional da Shoah.

Palavras-chave: Shoah. Romance. Anne Michaels.

Abstract: Read a novel accurately as fiction is our duty to readers; produce fictions capable of challenging our sense of reality, our vision of the world and of history, is, so to speak, the strict letter of the writer. The novel Peças em fuga, by Anne Michaels, three men, Jakob, Athos and Ben - your paper creatures - indulge in this craft. This article discusses, in this fictional novel, the memory of the Shoah.

Keywords: Shoah. Novel. Anne Michaels.

$\mathrm{O}$ assassinato rouba o futuro de um homem. Rouba dele a sua própria morte. Mas não deve roubar a sua vida.

Anne Michaels

"O tempo é um guia cego". Com essa imagem enigmática, tem início a primeira parte do romance Peças em fuga, da escritora canadense Anne Michaels. Como o cego Tirésias, no entanto, o tempo pode conduzir a revelações nefastas, mas imprescindíveis para que a história se dê a conhecer. A história de Jakob Beer virá à luz entrelaçada a inúmeras outras: narrativas míticas, literárias, documentais, fios emaranhados como algas que vêm à superfície. Assim como emerge, no sítio arqueológico de Biskupin, descoberto em 1933, na Polônia, toda uma cidade que permaneceu inteiramente preservada sob as águas por mais de mil anos. Do solo pantanoso, encoberta por jardins de junco, despontava lentamente, por obra de quase uma década de escavações, a vida de centenas de pessoas, com suas casas de madeira engenhosamente construídas, com seus passadiços, muros e portões, tigelas, jóias de bronze e âmbar, magníficos objetos que revelavam o pulsante cotidiano de artesãos e comerciantes da Idade do Bronze.

Nesse cenário impressionante, como um pequeno golem, Jakob também emerge da lama e salta do silêncio das ruas submersas de Biskupin para o mundo dos vivos. Algum tempo antes, dias, semanas, meses, talvez, o brutal assassinato de sua família havia imposto a fuga para a escuridão do alagadiço.

Aos 7 anos, pequeno o suficiente para "sumir por trás do papel de forro do armário", mimetizado ao gesso da parede, ele apenas ouviu:

A porta arrombada. Lascas de madeira saltando das dobradiças, estalando como gelo sob os gritos. Ruídos nunca ouvidos antes, arrancados da boca de meu pai. Depois, silêncio. Minha mãe estava pregando um botão em minha blusa. Ela guardava os botões num pires lascado. Ouvi a borda do pires em 
círculos no chão. Ouvi a chuva de botões, como dentinhos brancos. (MICHAELS, 1997a, p. 12)

A cena - toda ela reconstruída a partir dos sons gravados na memória - irá se desdobrar em imagens que acompanharão Jakob por longos anos. Imagens que começam a se formar naquela noite, após a última visão dos corpos desfigurados de seus pais, apenas duas formas no "amontoado de carne", em meio à casa destruída e enfumaçada. Um terceiro corpo também deveria estar ali. Porém, aos 15 anos, grande demais para o esconderijo, a irmã de Jakob, Bella, nunca mais será vista. A morte se apresenta sob várias formas. Algumas vezes, ela terá somente a face da ausência.

O que ocorre depois - a fuga desesperada para o rio, a sucessão de dias e noites transcorridos na solidão do pântano, o duro aprendizado da sobrevivência improvável - constitui uma seqüência narrativa no limite do inverossímil. Talvez porque a experiência judaica da Shoah muitas vezes se mostre tão contundente em sua crueza que desafia até mesmo as suas (im)possíveis representações na literatura. Para o escritor israelense David Grossman, "mesmo que tivéssemos a consciência da extensão desse horror, não saberíamos como lidar com ele. Não é, digamos, um fenômeno compreensível, nem mesmo numa dimensão metafórica".

A escrita de Michaels parece se dar conta da impossibilidade apontada por Grossman, conformando um outro tipo de projeto que não o de reproduzir acontecimentos históricos ou de abarcar a totalidade dos fatos que lhe servem de motivo. O que a declaração de Grossman (2007) permite discutir, frente ao romance de Michaels, é, assim, tanto a validade de se retomar um episódio histórico como mote para a criação artística, particularmente a literária, como também avaliar em que medida essa retomada é capaz de produzir um deslocamento do saber histórico constituído.

Peças em fuga tem sua maior força na produção imagética, numa composição que articula elementos factuais a um universo ficcional pontuado por um lirismo de nota melancólica. $\mathrm{O}$ apelo visual da linguagem, no caso dessa narrativa, é imediato, prescindindo, em alguma medida, do recurso descritivo para que se opere a apreensão dos fatos ali referidos. A reflexão sobre o conteúdo subjacente, segundo Michaels (1997b), virá depois, sem que o leitor tenha tempo de "se defender" do impacto provocado pelo vigor das imagens. Trata-se, ao que parece, de uma alternativa à interdição que a realidade impõe ao verbo, em seu uso denotativo, exatamente quando essa realidade se mostra tão imperiosa que não pode ser ignorada. Podemos pensar essa característica da escrita de Michaels a partir de uma tipologia dos processos imaginativos estabelecida por Italo Calvino (2002, p. 99) em suas propostas para a literatura deste milênio.

Teríamos, então, dois procedimentos que, provavelmente, estão na base da montagem textual da escritora: "o que parte da palavra para chegar à imagem visiva e o que parte da imagem visiva para chegar à expressão verbal". No primeiro procedimento, a linguagem é utilizada de modo a produzir um efeito de leitura que corresponderia a uma cena mental, uma visão que se forma, sem mediações, no cérebro do leitor. Ao privilegiar esse tipo de construção imagética, Michaels faz desdobrar, por vezes, uma temporalidade desde sempre inapreensível, a não ser pelo artifício da palavra. Isso ocorre, por exemplo, pelo recurso ao poder de condensação das listas, que provoca um efeito de flash back em que a materialidade da pedra, como uma película fílmica - ou como o Aleph borgiano -, serve de suporte e ativa uma memória que recobre séculos de história:

Aprendi o poder que atribuímos às pedras de reter o tempo humano. As tábuas de pedra dos Mandamentos. Montes de pedras tumulares, as ruínas de templos. Lápides, obeliscos, a Roseta, Stonehenge, o Partenon. (Os blocos cortados e carregados por prisioneiros nas minas de calcário de Golleschau. 
As lápides partidas nos cemitérios hebraicos e roubados para as calçadas polonesas; hoje cidadãos entediados, olhando a seus pés à espera do ônibus, ainda podem ler as inscrições.) (MICHAELS, 1997a, p. 30)

Mas é possível supor que Michaels tenha lançado mão também do segundo tipo de processo imaginativo descrito por Calvino. Considerando-se as inúmeras alusões a registros documentais da Shoah, pode-se deduzir que as incontáveis imagens do extermínio dos judeus colhidas durante a Grande Guerra e veiculadas nas mais diversas mídias - aspecto que abordaremos mais adiante tenham constituído um conjunto importante nas fontes utilizadas pela escritora em sua empreitada arqueológica. Essas imagens - fotografias, documentários, pinturas, monumentos - atuam, porém, na direção inversa do primeiro processo imaginativo mencionado acima, e "desenvolvem suas potencialidades implícitas" a partir da formação de "um campo de analogias, simetrias e contraposições", compondo um material que não é apenas visivo, mas igualmente conceitual, significante. O trabalho de escrita - um trabalho de tradução! - obedece, então, à busca de um equivalente verbal para a imagem visual, seguindo-se daí o desenvolvimento coerente da "impostação estilística" pretendida pelo escritor. Em um dado momento, é a escrita que assumirá a direção da narrativa, impondo uma lógica própria, "não restando à imaginação visual senão seguir atrás" (CALVINO, 2002, p. 104-105).

Essa dimensão lógica da escrita pode ser apreendida, por exemplo, em uma passagem do romance em que o narrador menciona fotografias de soldados nazistas sorrindo diante de prisioneiros sob tortura. A imagem visual - provavelmente um registro real - que deflagra o desenvolvimento narrativo recebe uma descrição sumária; porém, a linguagem verbal, em sua expressão meramente argumentativa, irá potencializar esse referente - o riso fotografado - ao limite do insuportável:

A política nazista ia além do racismo, era antimatéria, pois os judeus não eram considerados humanos. Um velho truque de linguagem, usado muitas vezes no curso da história. Os não-arianos não deviam nunca ser mencionados como humanos, mas como Figuren, Stücke - "bonecos", "madeira", "mercadoria", "trapos". Nenhum humano estava sendo morto na câmara de gás, só Figuren, de forma que não havia violação ética. Ninguém podia ser acusado de crime por queimar lixo, por queimar trapos e restos no sujo porão da sociedade. Tudo isso é que era, na verdade, um risco de incêndio! Que fazer senão queimar antes que significassem uma ameaça a você... (MICHAELS, 1997a, p. 127)

E será pela incursão nos domínios da significação lingüística que a contradição obliterada entre o ato dos soldados nazistas - a tortura e o assassinato - e sua justificativa - a reificação dos judeus - será exposta:

Se os nazistas desejavam a humilhação antes do extermínio, estavam admitindo exatamente aquilo que se empenhavam tanto em não admitir: a humanidade da vítima. Humilhar significa aceitar que sua vítima sente e pensa [que, portanto, não é Figur], que ela não só sente dor, mas que sabe que está sendo degradada. (MICHAELS, 1997a, p. 127)

Os dois processos, no entanto - o da palavra que busca a imagem visiva e o da imagem visiva que se transmuta em expressão verbal -, tratando-se do texto ficcional, pressupõem que o escritor deve “imaginar visualmente tanto o que seu personagem vê, quanto aquilo que acredita ver, ou que está 
sonhando, ou que recorda, ou que vê representado, ou que lhe é contado, assim como deve imaginar o conteúdo visual das metáforas de que se serve precisamente para facilitar essa evocação visiva" que constitui uma das formas mais complexas de representação do real (ver CALVINO, 2002, p. 99).

Como forma de representação do real e, principalmente, como espaço de ficcionalização - portanto, de invenção -, a literatura não se presta ao registro documental, não reclama um estatuto de verdade e, por isso mesmo, podemos pensar num certo privilégio do texto literário em relação a outros constructos culturais que se debruçam, em algum momento, sobre o mundo dos fatos. Ocorre que essa relativa liberdade permite à literatura uma significativa ampliação de fontes e, principalmente, franqueia múltiplas formas de abordagem e manuseio do que se apresentaria a nós como realidade. $\mathrm{O}$ texto literário, para se fazer, deve esmerar-se na prática da pilhagem e pode, assim, construir-se sobre o espólio do tempo, ao reler e reescrever, às vezes de modo a tornar irreconhecível, o patrimônio acumulado sob incontáveis camadas da cultura. $\mathrm{O}$ acesso a esse patrimônio coloca o escritor na posição de "um homem que escava", retomando aqui uma imagem criada por Walter Benjamin, para quem somente nos tornamos capazes de compreender um fato do passado quando perdemos o medo de "espalhá-lo como se espalha a terra, revolvê-lo como se revolve o solo", pois os fatos nada são além de "camadas que apenas à exploração mais cuidadosa entregam aquilo que recompensa a escavação" (BENJAMIN, 2000. p. 239).

No texto de Michaels, construído a partir de uma investigação arqueológica de outros textos documentos, arquivos, testemunhos -, o trabalho de escavação atua como metáfora da construção narrativa. As vozes de seus protagonistas darão a conhecer, ao longo do romance, não apenas uma memória simulada para dar-lhes vida, mas também fragmentos, vestígios de uma memória coletiva e histórica. Como o corpo milenar da verdadeira cidade de Biskupin, quase totalmente destruída pelo delírio megalômano de Heinrich Himmler, em 1940, esses vestígios emergem, no romance, para revelar as camadas de um passado não-ficcional, trazendo à luz alguns desvãos da história do povo judeu e da Shoah.

Organizado em duas partes - ou duas peças -, o romance de Anne Michaels deixa-se atravessar por incontáveis referências e discursos, a começar pelo título do livro, com uma remissão evidente a uma forma complexa de composição musical, "fuga", essencialmente polifônica, com base em um tema apresentado sob formas diversas. Ao mesmo tempo, uma das acepções dicionarizadas do termo aponta para a "retirada em desordem e com precipitação de um local, em razão de opressão ou ameaça", derivando dessa noção a terminologia militar para a "rápida retirada de tropas". Talvez esteja dada aí uma importante chave de leitura para essa narrativa, em que o entrecruzamento da criação poética e da imaginação com a dureza incorrigível de uma situação de guerra possa lançar uma compreensão outra sobre nossa história recente.

Junto à música, a arqueologia será também um dos registros dominantes na narrativa. A trajetória de seus protagonistas - Jakob, Athos e Ben - será guiada pela necessidade vital de descortinar o passado, não apenas como forma de compreender a dimensão trágica do tempo individual de cada um, mas, talvez, como único meio possível de sobreviver a essa compreensão. A primeira parte do romance simula o relato das memórias de Jakob Beer. Coleante, disperso ao longo do tempo - esse "guia cego" -, o testemunho de Jakob, um pequeno memorial, será obra de uma lenta investigação do passado, um esforço de rememoração transformado em poemas e, principalmente, em dois diários que serão encontrados somente após sua morte. E esse será o eixo da segunda parte do livro, narrada por Ben, filho de judeus sobreviventes. Após um breve e único encontro, Ben vê-se fascinado pela figura multifacetada de Jakob, professor, poeta, tradutor. Anos depois, ele irá reunir sua obra, empenhandose na publicação póstuma de seus diários, num inescapável exercício de reescrever a própria história, dolorosamente espelhada nas memórias de Beer. Essa dupla escrita - a do passado e a do compilador Arquivo Maaravi: Revista Digital de Estudos Judaicos da UFMG. Belo Horizonte, v. 1, n. 1, out. 2007. ISSN: $1982-3053$. 
- institui, portanto, uma das premissas conceituais da condição pós-moderna, qual seja a do narrador de experiências alheias.

Não sendo uma escritora de ascendência judaica, Anne Michaels se alinha a uma vertente escritural que tem precisamente na simulação, no fingimento, uma estratégia narrativa importante, construindo um relato baseado numa memória simulada, numa experiência a que ela mesma não teve acesso. Seus personagens operam, por esse artifício, como uma metáfora da narrativa de testemunho, em que a ação narrada é a própria experiência que se tem dela, sendo esse aspecto, em última análise, o que emprestaria autenticidade ao relato. Para Michaels, no entanto, a crença de que "as pessoas que não viveram os fatos não podem contá-los está se modificando", e, além disso, o distanciamento temporal da guerra e o envelhecimento dos sobreviventes da Shoah impelem as novas gerações a conhecer e a escrever essa história. E, parafraseando uma fala de Jakob, seu personagem, a escritora resume a importância dessa escrita: "se não dermos uma utilidade à memória, ela morre". (1997b, p. 6)

No romance de Michaels, a memória, como recomenda Benjamin (2000. p. 239), "não é um instrumento para a exploração do passado; é, antes, o meio. É o meio onde se deu a vivência, assim como o solo é o meio no qual as antigas cidades estão soterradas". Talvez por isso, após a morte dos pais, Jakob tenha se refugiado na terra, passando um longo período na floresta, às margens do rio Gasawka. Para se manter em segurança, o menino dorme coberto pela lama, deixando apenas parte do rosto a descoberto, voltado para o céu, à espreita: "Meus dias no solo eram um delírio de sono e atenção" (MICHAELS, 1997a, p. 14). Enquanto cava sua cama no lodaçal, noite após noite, Jakob começa a construir o que será sua memória da dor:

Fiquei olhando o escuro transformar-se em luz roxo-alaranjada sobre a cidade; cor da carne se transformando em espírito. Eles subiram. Os mortos passaram sobre mim [...] Lutei para ir com eles, subir com eles, desgrudarme do chão como papel com as beiradas descolando. Entendo por que enterramos nossos mortos e marcamos o lugar com pedra, a coisa mais pesada e mais permanente que conhecemos: porque os mortos ficam por toda parte, menos no chão. (MICHAELS, 1997a, p. 13)

E despede-se de seus mortos:

senti de repente que minha mãe estava dentro de mim. Deslizando por nervos, por debaixo de minha pele como antes costumava andar pela casa de noite, jogando fora coisas, arrumando coisas. Ela havia parado para se despedir e ficou presa, com tanta dor, querendo subir, querendo ficar. Dependia de mim permitir que se fosse, um pecado impedir que subisse. Rasguei minhas roupas, puxei meus cabelos. Ela se foi. (MICHAELS, 1997a, p. 13)

Ao sair do esconderijo, do lamaçal que havia sido seu abrigo contra os homens da Gestapo, Jakob será salvo por um cientista grego que integrava a equipe de pesquisadores em trabalho nas escavações de Biskupin. Envolto em lama, faminto, "louco de surdez. Orelhas entupidas de turfa", ele grita, batendose no peito, "a única frase que sabia em mais de uma língua", em polonês, em alemão, em iídiche: "judeu sujo, judeu sujo, judeu sujo" (MICHAELS, 1997a, p. 17). Em múltiplas línguas se dará a comunicação e o entendimento entre o pequeno Jakob e o grego Athos. Um encontro assinalado pela ironia na ambigüidade da fala desesperada do menino judeu, ali, literalmente sujo de lama, mas que recupera, nos vários idiomas, o epíteto ofensivo, o tratamento anti-semita tantas vezes conferido ao seu povo. 
Esquivando-se dos soldados nazistas, no banco de trás de um carro, outra fuga. Novamente submerso, agora sob o casaco protetor de Athos, Jakob Beer será levado para a Grécia. Na noite em que chegam ao seu destino, Athos sentencia: "Eu vou ser seu koumbaros [...] A gente tem que se ajudar. Se não, o que é que somos?" (MICHAELS, 1997a, p. 18). Na fé ortodoxa grega, mais que um padrinho nas cerimônias de casamento ou batismo, um koumbaros (algo como "o melhor dos homens") é um guia, um pai espiritual que assume a responsabilidade - como um dever e uma honra - de cuidar daquele que o escolheu como o melhor entre outros homens. No contexto da narrativa, essa responsabilidade manifesta na fala de Athos pode ser entendida, a partir de uma reflexão de Zygmunt Bauman (1998), como parte constitutiva e inalienável da condição subjetiva: tornar-se sujeito implica, fundamentalmente, tornar-se responsável diante do outro, não importando aí qualquer expectativa de reciprocidade.

Trata-se de uma responsabilidade incondicional, que se impõe pela simples existência do outro enquanto objeto da minha consciência. Não há, aí, nenhuma relação de dependência quanto ao conhecimento anterior acerca das qualidades intrínsecas do outro: "ela precede tal conhecimento. Não depende de uma intenção interessada pelo objeto: precede tal intenção. Nem o conhecimento nem a intenção contribuem para a proximidade do outro, para o modo especificamente humano de conjunção". Partindo dos estudos de Emmanuel Lévinas sobre a noção de alteridade, conclui Bauman (1998, p. 211-212): "Proximidade significa responsabilidade e responsabilidade é proximidade. A discussão da prioridade relativa de uma ou de outra é reconhecidamente gratuita, pois nenhuma é concebível sozinha". E é dentro desses parâmetros que a relação entre os dois personagens parece consolidar-se. A distância aparentemente intransponível das diferenças lingüísticas será gradual e mutuamente superada pela responsabilidade que, segundo o sociólogo polonês, deve conformar as relações intersubjetivas.

Na ilha de Zakynthos, terra alta e ventosa, marcada por terremotos, e cantada por Homero, Plínio e Estrabão, Jakob passaria quatro anos, sem sair sequer à porta da pequena casa de Athos, a quinhentos metros acima do nível do mar. Ali, cercados de amostras de rochas, fósseis, fotos, vasilhames, pentes pré-históricos, livros, iam aprendendo um a língua do outro: um pouco do iídiche de Jakob, um pouco do polonês dos dois, o grego e o inglês de Athos; o alfabeto hebraico revisado diariamente, sob a justificativa do amigo geólogo: "É o seu futuro que você está lembrando" (MICHAELS, 1997a, p. 22).

No silêncio das noites, Jakob ouvia: a vida de bactérias de três milhões de anos, o granito, expedições à Antártica, o sal, a independência grega, o basalto, poesia clássica, lendas vikings, calcário, Solomos, Keats, Marco Polo. Histórias sobre a família de Athos, sua infância, seus pais, como ele aprendera a fazer pipas com o irmão, Nikos - uma vasta enciclopédia da biografia do outro.

Ouvia também - pela voz das poucas visitas que recebiam - as histórias da guerra hedionda que se desenrolava logo abaixo de seus pés: Corfu, Salonika, Creta... dia após dia, as comunidades judaicas das ilhas estavam sendo transferidas para o fundo do mar.

Como rochas sedimentares, o mundo de Jakob formava-se, morosamente, por sucessivas camadas de imagens depositadas em sua memória, como o lodo do rio onde aprendera a conviver com o terror. Nesse universo assombrado pela lembrança, e, mais, pela necessidade extrema de não esquecer, Jakob assemelhava-se ao calcário, "aquele veio esmagado de memória, aquela pedra viva, história orgânica espremida em maciças tumbas montanhosas" (MICHAELS, 1997a, p. 31). Era, agora, semelhante às peças enterradas pelos judeus no solo dos guetos: o tallith, as velas, pratos, cartas, brinquedos, livros, fotos, retalhos de renda, diários jamais encontrados; o solo de toda a Europa parecia, assim, guardar esses tesouros e configurava-se como um arquivo e um memorial. O acervo (ou arquivo) europeu 
também é composto de vestígios, de objetos da arqueologia, da tradição e da memória judaica. O texto de Michaels revela, em sua construção, mesclando as culturas grega, polonesa, judaica, cristã, esse solo misto, variegado.

Resguardar objetos da destruição parece ser um ato ligado ao nosso instinto mais íntimo de preservação. É como se confiássemos a eles a tarefa de contar a nossa história quando não mais o pudermos fazer. Temos a esperança de que sejam capazes de falar, no futuro, sobre nossa vida comezinha, nossos projetos, nossas rotinas e afetos; resgatados do chão das cozinhas, do fundo dos rios, do oco das paredes, do forro dos sótãos, esses objetos são, em sua presença silenciosa, a prova de que existe um tempo a ser rememorado.

Cada objeto recuperado seria, então, como uma fagulha, uma cintilação do passado, a lançar luz sobre um rosto anônimo, uma troca de presentes, um acordo político. O passado vem, assim, em lampejos, fracionado, e devemos sabê-lo para sempre lacunar, falho, descontínuo. A tarefa de articular historicamente o passado, como bem assinala Walter Benjamin (1994, p. 224), "não significa conhecê-lo 'como ele de fato foi'. Significa apropriar-se de uma reminiscência, tal como ela relampeja no momento de um perigo". No contexto da Shoah, estava em perigo tanto a vida dos indivíduos quanto a existência das tradições nas quais estavam inscritos. A extensão de uma ameaça dessa ordem traz aqui uma dimensão lingüística importante. Traduzido por "catástrofe", o termo hebraico Shoah "exprime, ao mesmo tempo, que essa catástrofe, ao golpear suas vítimas, também atingiu a civilização na qual ela se tornou possível" (NASCIMENTO, 2006).

A impossibilidade de se conhecer os acontecimentos tais como ocorreram em sua totalidade não pode implicar, portanto, qualquer imobilismo diante de suas repercussões. A literatura e também o cinema - talvez um pouco mais que outras artes, por suas especificidades expressivas - inserem-se, assim, no campo das responsabilidades, pois está implícita na língua, em seus usos, em suas aplicações, uma posição ética e política que não deve escapar à ficcionalização dos fatos históricos e às escolhas estéticas aí presentes.

Com que língua, então, se pode contar o que aconteceu? Que vocábulos são capazes de expressar a experiência de integrar uma orquestra que toca para encobrir os gritos de amigos e familiares que morrem num campo de concentração? Que idioma contém palavras para traduzir o som da morte, da tortura, da fome, da humilhação?

Em entrevista, Anne Michaels (1997b) revela que escrever Peças em fuga constituiu uma tentativa de resposta a questões humanas essenciais, a primeira delas: "o que significa viver moralmente, levar uma vida moral?" (grifo do original).

A essa altura, cabe retomar o pensamento de Zygmunt Bauman em Modernidade e holocausto. Para esse estudioso, sendo a substância da moralidade "um dever em relação ao outro (enquanto distinto de uma obrigação) e um dever que precede todo interesse, as raízes da moralidade penetram bem mais fundo que os arranjos societários, como cultura ou estruturas de dominação" (1998, p. 212). Prosseguindo em seu raciocínio, Bauman ressalta que a moralidade não é um produto da sociedade, mas algo que a antecede e que ela manipula, explora, redireciona; ou seja, a moral seria uma condição para a existência humana em sociedade. Não se trata, obviamente, de uma categoria ontológica: "O comportamento moral é concebível apenas no contexto da coexistência, do 'estar com os outros', isto é, no contexto social; mas não deve seu aparecimento à presença de agências supra-individuais de treinamento e imposição, ou seja, ao contexto societário" (p. 207). Assim compreendida, a capacidade moral excetua-se do contexto que legitimou os crimes nazistas dentro, particularmente, da sociedade 
alemã - crimes perfeitamente conformes aos princípios morais em vigor naquele tempo e naquele lugar.

Viver moralmente, nesse sentido, permitiria, sem nenhum paradoxo, uma espécie de insubordinação moral "face a princípios socialmente sustentados e numa ação abertamente em desafio da solidariedade e consenso sociais"; talvez, como assinala Hannah Arendt, citada por Bauman, tal insubordinação constitua a única possibilidade para que "os seres humanos sejam capazes de distinguir certo de errado mesmo quando tudo o que têm a guiá-los é seu próprio juízo" (p. 205-206). No contexto da Shoah, viver moralmente implicaria, portanto, entrar em franco desacordo com o estado de coisas consolidado para sustentar o Terceiro Reich e sua máquina de extermínio. E, no âmbito da narrativa, essa questão está amplamente representada, como ocorre no seguinte trecho:

A ironia é uma tesoura, uma forquilha de achar água, sempre apontando para duas direções. Se o ato mau não pode ser apagado, tampouco pode o bom. É um sistema de medida tão acurado quanto qualquer outro numa sociedade: qual é o menor ato de generosidade que se considera heróico? Naqueles dias, ser moral exigia apenas o mais minúsculo movimento - um micrometro - de olhos se desviando ou piscando, enquanto um homem atravessa correndo um campo. E aqueles que davam água e pão! Esses penetravam em um reino mais alto que o dos anjos pelo simples fato de terem permanecido no nível do lodo humano. (MICHAELS, 1997a, p. 124)

Segundo Jürgen Habermas, "Auschwitz mudou as bases da continuidade das condições de vida na história". O que era moralmente inconcebível é, agora, marca inapagável do passado da humanidade, uma fratura irreversível naquilo "que representa a camada mais profunda de solidariedade entre todos os que vestem um rosto humano" (HABERMAS apud HUYSSEN, 2000, p. 86).

Retomar a experiência da Shoah como motivo literário é, nesses parâmetros, reler e reescrever a história a contrapelo, como sugere Benjamin, assumindo-nos como parte integrante da cultura que o produziu em todo o seu barbarismo, num esforço de transpor a barreira diante da qual tudo se detém: o inimaginável, indizível e irrepresentável terror (ver HUYSSEN, 2000, p. 85). Não se trata de atribuir à literatura uma funcionalidade, uma utilidade, no sentido estrito, mas de entendê-la no corpo social e, principalmente, na dinâmica de uma cultura que se pensa no momento mesmo em que se produz.

É pertinente, nesse ponto, a reflexão de Andreas Huyssen sobre a recente proliferação de representações do episódio da Segunda Guerra Mundial e, particularmente, da Shoah. Sua crítica quanto ao risco da sua banalização procede se levarmos em conta as características da cultura contemporânea e das mídias de massa.

De modo geral, certo distanciamento parece necessário para que se possa falar de um acontecimento pretérito. O esquecimento constitui, nesse processo, um mecanismo natural de seleção da memória, em que se determina o que deve ser lembrado, recuperado dos escombros acumulados no tempo. No entanto, quando se trata da ação de extermínio empreendida pela máquina de guerra nazista, essa abordagem seletiva fica comprometida pela própria incapacidade que temos de lidar com as informações. Quanto mais documentados os fatos, mais nos parecem irreais, impossíveis, abomináveis, tal o horror que provocam.

Contudo, seja por um procrastinado senso de justiça política, seja por uma perversa motivação mercadológica, nas últimas décadas, a Shoah e seus aspectos conexos, como o nazismo, o fascismo e temas étnico-religiosos, vêm ganhando amplo espaço na produção cultural ocidental. Em versões facilitadoras, muitas vezes glamorizadas, o evento histórico perde sua força de significação, desejável, em última instância, para que possamos conectar a experiência do passado com o que nos tornamos no presente. Estamos diante de um fenômeno inerente à cultura de massas, em que a repetição 
exaustiva banaliza o extraordinário, amortiza a capacidade de estranhamento e de choque diante do hediondo.

Para Huyssen (2000, p. 78-9), "a proliferação indiscriminada do próprio lugar-comum pode ser um sinal de sua fossilização traumática, de sua permanência na prisão de uma fixação melancólica que atinge muito mais pessoas além das vítimas e dos perpetradores". É possível que esse processo de fossilização da memória ofereça um risco, em alguma medida, mais grave que o do esquecimento, ao operar fora do jogo ficcional, um aniquilamento do sentido de distância entre o passado e o presente, e, principalmente, entre o real e o simulacro. Estaria aí um terreno propício para que vicejem teorias negacionistas e tendências de revisionismo histórico.

A contrapartida a essa banalização estaria no trato criterioso com o que Huyssen (2000, p. 84) chama de "núcleo duro de fatos", resultante do conhecimento acumulado pela historiografia, pelos arquivos, testemunhos, documentários, e através do qual torna-se possível às novas gerações aproximarem-se do que aconteceu por uma "estratégia mnemônica que reconhece o evento em sua alteridade e para além da identificação ou da empatia terapêutica, mas que incorpora fisicamente um pouco do terror e da dor no lento e persistente ofício de rememoração" (HUYSSEN, 2000, p. 85).

Nesse âmbito, o romance de Michaels, ao simular uma apropriação da memória alheia - em alguma medida, extraída de um acervo coletivo, de um "núcleo duro de fatos" -, configura uma cadeia metafórica que pode interessar ao estudo das nossas relações com um passado traumático. Os três personagens centrais, Athos, Jakob e Ben, relacionam-se com esse passado de modo diverso, mas todos passam, de algum modo, pela escrita.

Athos, um humanista, arqueólogo, geólogo, "poliglota medíocre", esgota suas forças num projeto obsessivo. No dia em que encontra Jakob, em Biskupin, ele abandona o sítio para salvar o menino. Mas ele também será salvo nessa fuga, pois logo que eles escapam, os soldados nazistas invadem a área de escavação e assassinam cinco de seus colegas cientistas. Com o fim da guerra, dedicando-se a pesquisas exaustivas, ele dará início à escrita de um livro, ironicamente intitulado Prestando falso testemunho. Era "seu registro de como os nazistas violaram a arqueologia para distorcer o passado. Em 1939, Biskupin já era um sítio famoso, apelidado 'Pompéia polonesa'. Era, porém, prova de uma avançada cultura não germânica; Himmler ordenou que fosse exterminada" (MICHAELS, 1997a, p. 83). Deixando-se consumir na tarefa de revolver o solo da história, esse personagem transplanta para o terreno fértil da ficção - o romance de Michaels, que lemos no presente - uma importante parcela do passado da humanidade.

Jakob, após a morte de Athos, retomará o projeto inacabado do amigo, compilando suas anotações, pesquisando os documentos acumulados, durante anos, pelo outro. Em Toronto, para onde os dois haviam se transferido depois da guerra, ele irá se tornar um tradutor e, mais tarde, poeta, quando também se decide por escrever as próprias memórias. Acostumado com os meandros da tradução, essa "espécie de transubstanciação", ele fará esse exercício de apropriação do olhar, da emoção, das lembranças, da palavra do outro. Ao dar continuidade à escrita de Athos, ao escrever por Athos, ele estará acessando uma memória alheia, e assumindo para si essa memória.

O mesmo acontecerá, anos depois, com Ben. Nascido em Toronto, no pós-guerra, esse personagem será marcado, desde muito cedo, com o peso asfixiante da Shoah, continuamente presentificada na figura sombria de seu pai, sobrevivente de um campo de concentração. Ben ainda viverá por muito tempo sob essa terrível lembrança transmitida não pela palavra, mas por sua quase total ausência - na casa da família, o silêncio parecia ter a função de barrar a memória, como se, ao ser proferida, a palavra fizesse reviver o passado. Adulto, além de metereologista e professor, ele se tornará escritor. 
Após um único encontro com Jakob Beer - poeta já consagrado -, sua vida irá adquirir um novo sentido. Depois da morte de Jakob, ele partirá para a Grécia atrás de seus escritos. Ali, também ele assumirá a memória alheia, uma memória que ele irá escavar na casa de Jakob, que ele passa a habitar como um santuário. Numa espécie de simbiose entre o seu presente e o passado de Jakob, ele irá recuperar e compreender sua própria biografia, relendo, de viés, também a história de seu pai, de algum modo inscrita nas recordações de Jakob, anotadas em dois pequenos cadernos encontrados acidentalmente.

Em tempos distintos, esses três personagens se encontram, e se imbricam, pelo exercício da escrita, compartilhando uma memória esfacelada, dispersa no tempo e no espaço, um baú em desordem. É nesse entrecruzamento de experiências emprestadas que eles configuram, dentro da narrativa, uma metáfora da literatura de testemunho. E, às avessas, pelo falseamento, essa literatura se inscreve também na História, esse imenso domínio das "coisas ditas", lembrando a expressão de Foucault, em A arqueologia do saber (2004). É assim que a literatura é capaz de reescrever a história, narrando experiências, vividas ou não, mas que precisam ser contadas.

Ler um romance rigorosamente como ficção é o nosso dever de leitores; produzir ficções capazes de desafiar o nosso senso de realidade, a nossa visão do mundo e da história, é, por assim dizer, o estrito ofício do escritor. No romance de Michaels, três homens, Jakob, Athos e Ben - suas criaturas de papel -, se entregam a esse ofício. Cada um fez, a seu tempo, sua expedição arqueológica, dando ao passado a chance de expor-se aos olhos do presente, trazendo à superfície uma peça do mosaico arruinado pelo tempo, para sempre incompleto. Ao vasculharem as sombras da própria memória, eles precisaram acessar a memória alheia, uma memória que é de todos e que, por isso, precisa ser escrita e tornada pública, precisa ser compartilhada e transmitida ao futuro. Por quê? A resposta vem pela voz de Jakob Beer: "A lembrança morre a menos que tenha uso". Ou, como diria Athos: "Se não tem mais a terra, mas se tem a lembrança da terra, então dá para se fazer um mapa" (MICHAELS, 1997a, p.146).

*Vivien Gonzaga e Silva é Licenciada em Letras pela UFMG e Mestranda do Programa de PósGraduação em Letras: Estudos Literários da UFMG.

\section{Referências}

BAUMAN, Zygmunt. Modernidade e holocausto. Trad. Marcus Panchel. Rio de Janeiro: Jorge Zahar Editor, 1998.

BENJAMIN, Walter. Obras escolhidas. Magia e técnica, arte e política. v. I. 7. ed. Trad. Sergio Paulo Rouanet. São Paulo: Brasiliense, 1994.

BENJAMIN, Walter. Obras escolhidas. Rua de mão única. v. II. 5. ed. Trad. Rubens Rodrigues Torres Filho e José Carlos Martins Barbosa. São Paulo: Brasiliense, 2000.

CALVINO, Italo. Seis propostas para o próximo milênio. Trad. Ivo Barroso. 2. ed. São Paulo: Companhia das Letras, 2001.

FOUCAULT, Michel. A arqueologia do saber. Trad. Luiz Felipe Baeta Neves. 7. ed. Rio de Janeiro: Forense Universitária, 2004.

GROSSMAN, David. Ser judeu é ser um eterno outsider - Entrevista. O Estado de S. Paulo. Disponível em: . Acesso em 26 maio 2007.

HUYSSEN, Andreas. Seduzidos pela memória: arquitetura, monumentos, mídia. Trad. Sergio Alcides. Rio de Janeiro: Aeroplano Editora; Universidade Candido Mendes; Museu de Arte Moderna - RJ, 2000. 
LÉVINAS, Emmanuel. Entre nós: ensaios sobre a alteridade. 3. ed. Trad. Pergentino Stefano Pivatto (Coord.); Evaldo Antônio Kuiava, José Nedel, Luiz Pedro Wagner e Marcelo Luiz Pelizolli. Petrópolis: Editoras Vozes, 2004.

MICHAELS, Anne. Peças em fuga. Trad. José Rubens Siqueira. São Paulo. Companhia das Letras, 1997a.

MICHAELS, Anne. Sem utilidade, a memória morre. Entrevista. Jornal do Brasil. Caderno Idéias Livros. Rio de Janeiro, 17 maio 1997b.

NASCIMENTO, Lyslei. Entrevista. Interletras - Revista Transdisciplinar de Letras, Educação e Cultura da UNIGRAN. v. 1, n. 5, jul./dez. 2006. Disponível em: . Acesso em 29 jun 2007.

SANTIAGO, Silviano. Nas malhas da letra. Ensaios. Rio de Janeiro: Rocco, 2002. 